\title{
A desindustrialização na região Nordeste
}

\author{
Deindustrialization in the Northeast region \\ La désindustrialisation du Nord-Est
}

La Desindustrialización en la región Nordeste

\author{
José Alderir da Silva ${ }^{1}$ \\ Recebido em 05/08/2017; revisado e aprovado em 08/08/2017; aceito em 01/11/2017 \\ DOI: http://dx.doi.org/10.20435/inter.v0i0.1679
}

\begin{abstract}
Resumo: Este artigo tem por objetivo observar a evolução da indústria de transformação na região Nordeste, em particular verificar se a região sofre de um processo de desindustrialização. A indústria de transformação no Brasil tem apresentado um processo de desindustrialização, passando de uma participação de $32 \%$ do PIB em 1986 para cerca de 10\% em 2014. Diante disso, busca-se analisar se a indústria de transformação na região Nordeste e seus estados seguiu a trajetória da indústria nacional, ou seja, de desindustrialização. Palavras-chave: desindustrialização; região Nordeste; Bahia.

Abstract: This article aims to observe the evolution of the processing industry in the Northeast region, in particular to verify if the region suffers from a deindustrialization process. The manufacturing industry in Brazil has undergone a process of deindustrialization, from a 32\% share of GDP in 1986 to about 10\% in 2014. In the light of this, it is sought to analyze if the manufacturing industry in the Northeast region and its states Followed the trajectory of the national industry, that is, deindustrialization.
\end{abstract}

Keywords: desindustrialization; Northeastern region; Bahia.

Résumé: Cet article vise à observer l'évolution de l'industrie manufacturière dans le nord-est, vérifier en particulier que la région souffre d'un processus de désindustrialisation. L'industrie de la fabrication au Brésil a montré processus de désindustrialisation, d'une part de 32\% du PIB en 1986 à environ 10\% en 2014. Par conséquent, nous essayons d'analyser si l'industrie de transformation dans la région du Nord-Est et ses états il a suivi la trajectoire de l'industrie nationale, à savoir la désindustrialisation.

Mots-clés: désindustrialisation; région du Nord-Est; Bahia.

Resumen: Este artículo tiene por objetivo observar la evolución de la industria de transformación en la región Nordeste, en particular verificar si la región sufre de un proceso de desindustrialización. La industria de transformación en Brasil ha presentado un proceso de desindustrialización, pasando de una participación del 32\% del PIB en 1986 a cerca del 10\% en 2014. Frente a ello, se busca analizar si la industria de transformación en la región Nordeste y sus estados Siguió la trayectoria de la industria nacional, es decir, de desindustrialización. Palabras clave: desindustrialización; región Nordeste; Bahia.

\section{INTRODUÇÃO}

A indústria de transformação no Brasil tem apresentado um processo de desindustrialização, passando de uma participação de 32\% do PIB, em 1986, para cerca de 10\%, em 2014. Diante disso, busca-se analisar se a indústria de transformação na região Nordeste e seus estados seguiu a trajetória da indústria nacional, ou seja, de desindustrialização. Com isso, será possível identificar se a desindustrialização no Nordeste ocorre de forma homogênea ou se tem concentrado em algum estado.

Assim, este artigo tem por objetivo observar a evolução da indústria de transformação na região Nordeste, em particular verificar se a região sofre de um processo de desindustrialização.

Recentemente tem ocorrido um intenso debate sobre o processo de desindustrialização na economia brasileira, obtendo significativos avanços no que diz respeito às causas, consequências e, principalmente, sobre a ênfase dada ao papel da indústria para o desenvolvimento do Brasil.

\footnotetext{
${ }^{1}$ Universidade Federal do Semi-Árido (UFERSA), Angicos, Rio Grande do Norte, Brasil.
} 
Os denominados novos-desenvolvimentista defendem a hipótese de que a economia brasileira sofre de um processo de desindustrialização derivado da doença holandesa, esta última causada pela sobreapreciação real do câmbio. Segundo Oreiro e Feijó (2010) e Bresser-Pereira e Marconi (2008), o aprofundamento da abertura comercial e financeira da economia brasileira, que teve início na década de 1980, combinado com o boom das commodities nos anos 2000, foi o principal responsável por essa sobreapreciação cambial.

Por outro lado, parte da ortodoxia, Barros e Pereira (2008), argumenta que o Brasil não padece de um processo de desindustrialização, mas passa por um processo de modernização da estrutura produtiva do país propiciada pelo barateamento dos bens de capital importados. Diante disso, a dificuldade de alguns setores seria um processo natural de seleção das atividades que o país possui vantagens comparativas e, não um processo de desindustrialização.

A outra parte da ortodoxia, Bonelli e Pessôa (2010) e Bonelli e Pinheiro (2012), defende a tese de que o país estava sobreindustrializado, ou seja, com um nível de industrialização acima do permitido pelos seus fatores produtivos antes da década de 1980, de modo que a desindustrialização no Brasil não passa de um retorno ao padrão determinado por seus fatores produtivos.

Além dessas abordagens, Oliveira e Silva (2016) destacam outras duas: a intrassetorial e a da Unicamp. A primeira define a desindustrialização como uma mudança na estrutura interna da indústria de transformação em direção a setores intensivos em recursos naturais e em mão de obra. Sendo assim, ainda não se pode afirmar que o Brasil esteja passando por um processo de desindustrialização (ver NASSIF, 2008).

Na abordagem da Unicamp, destacam-se as teses de pelo menos dois autores: Cano (2014) e Hiratuka e Sarti (2015). Para o primeiro autor, a desindustrialização no Brasil se deve a (a) abertura comercial e financeira ilimitada; (b) crescimento dos setores agrícola e mineral acima do da indústria de transformação, na última década; (c) sobreapreciação cambial; (d) baixo crescimento da economia internacional; (e) alta taxa de juros; (f) redução dos investimentos interno e externo na indústria de transformação. Já Hiratuka e Sarti (2015), afirmam que existem transformações na estrutura produtiva global que ainda não receberam a devida atenção no debate sobre a desindustrialização no Brasil, como a reorganização das estratégias globais da atividade produtiva por parte das empresas transnacionais, ii) a interferência da China não apenas nos preços das commodities, mas também nos preços dos bens manufaturados; iii) o aparecimento de novos competidores e a abertura de espaços seletivos para a inserção dos países em desenvolvimento nas redes de produção e, iv) o reforço de políticas nacionais dos países desenvolvidos, diante do cenário pós-crise, que objetivaram incentivar a mudança tecnológica e a reestruturação industrial, como forma de recuperar o dinamismo econômico.

Contudo a desindustrialização na economia brasileira dentro desse debate ${ }^{2}$ é tratada de forma homogênea, como se todas as regiões e estados se encontrassem nas mesmas circunstâncias, sendo a discussão na perspectiva regional/estadual praticamente desconsiderada.

Dentro de uma perspectiva regional/estadual, é possível que uma região/estado tenha aumentado sua participação enquanto outra(o) tenha diminuído. Em outras palavras, a primeira tem seguido um processo natural de industrialização, enquanto a segunda região/estado sofre

\footnotetext{
${ }^{2}$ Para outras teses sobre o processo de desindustrialização na economia brasileira, vide Squeff (2012), Vergnhanini (2013), Silva e Lourenço (2014) e Oreiro e Marconi (2014).
} 
de desindustrialização, de modo que as políticas adotadas devem ser distintas para ambos estados. Diante disso, este trabalho tenta amenizar essa lacuna existente no debate em torno da economia brasileira, chamando a atenção para a análise da desindustrialização na perspectiva regional/estadual.

Este paper se divide em mais três seções além desta introdução. A primeira seção tem por objetivo revisitar o conceito de desindustrialização. Do mesmo modo, a seção seguinte busca observar se os estados da região Nordeste sofrem de um processo de desindustrialização. Por fim, as considerações finais.

\section{REVISITANDO O CONCEITO DE DESINDUSTRIALIZAÇÃO}

A indústria de transformação é de suma importância para o crescimento econômico. Se compararmos com os demais setores da economia, a indústria possui efeitos de encadeamentos tanto para frente quanto para trás. Para Hirschman (1958), os efeitos de encadeamento são os transbordamentos através de externalidades positivas para os demais setores que geram maior dinamismo na economia.

Além desses efeitos de encadeamentos, Kaldor (1957) também considera a indústria um setor diferencial em relação aos demais setores da economia por possuir elevada produtividade e maiores economias estáticas e dinâmicas de escala, maior capacidade de gerar crescimento e progresso tecnológico para toda economia e por aliviar as restrições externas ao crescimento, uma vez que os produtos industriais possuem maior elasticidade renda da demanda. Devido a essas características, Kaldor (1967) observou que os países industrializados tendem a apresentar crescimento superior aos países cuja produção seja intensiva em recursos naturais.

Segundo Oreiro e Feijó (2010), a indústria é a fonte geradora dos "retornos crescentes de escala e a fonte difusora do progresso técnico que permite o relaxamento da restrição externa ao crescimento de longo prazo".

Desse modo, a desindustrialização no sentido negativo do termo pode prejudicar o dinamismo da economia. No entanto a desindustrialização nem sempre é ruim para a economia, representando na verdade um processo natural do desenvolvimento econômico. Portanto é necessário definir a desindustrialização conceitualmente para que não ocorram erros de interpretação quando for realizada a análise para a economia da região Nordeste.

O conceito de desindustrialização aparece com maior evidência no final da década de 1980, com o trabalho pioneiro de Rowthorn e Wells (1987), em que esses autores a definem com a redução da participação do emprego da indústria de transformação no emprego total. Para os autores em questão, existem pelo menos dois tipos de desindustrialização: a positiva e a negativa.

A desindustrialização positiva ocorre quando a perda de empregos se tem de forma relativa e absoluta, mas que se trata de um processo natural do desenvolvimento econômico. Nesse caso, a indústria de transformação já é altamente produtiva, de modo que, apesar da redução do emprego, tem-se um aumento da produção. No entanto essa redução do emprego relativa e absoluta na indústria de transformação não provoca aumento do desemprego, pois os trabalhadores da indústria de transformação que perderam seu emprego são deslocados para o setor de serviços. Com isso, a economia se encontra sempre em uma situação próxima do pleno emprego. Por isso, Rowthorn e Wells (1987) afirmam que a desindustrialização positiva não é um fenômeno patológico, mas um sintoma de sucesso econômico. 
Por outro lado, a desindustrialização negativa se trata de um fenômeno patológico que pode afetar uma economia em qualquer fase do desenvolvimento econômico. Nesse caso, o emprego ocioso gerado pela indústria de transformação não será absorvido pelo setor de serviços, de modo que o desemprego aumenta. Portanto trata-se de um sintoma de fracasso econômico.

Rowthorn e Wells (1987) também mencionam que a desindustrialização pode ocorrer quando se têm mudanças no comércio internacional de um país. Ou seja, quando por alguma razão, o país deixa de exportar bens manufaturados para exportar outros tipos de bens, como commodities por exemplo. Diante disso, ocorrerá um deslocamento de recursos e de emprego do setor manufatureiro para o setor beneficiado pelo novo padrão de comércio internacional do país. Com efeito, haverá a queda de participação do emprego industrial no emprego total.

Outros autores mais contemporâneos, como Palma (2005), Bresser-Pereira (2008) e Oreiro e Feijó (2010), passaram a designar esse tipo de desindustrialização por doença holandesa, cuja razão, segundo Bresser-Pereira e Marconi (2008), se encontra na sobreapreciação cambial.

Não obstante, com o objetivo de incorporar os efeitos kaldorianos mencionados anteriormente, o conceito de desindustrialização foi redefinido por Tregenna (2009). Para a autora, a desindustrialização pode ocorrer tanto em termos de emprego como de valor adicionado (V.A.). Assim, a desindustrialização pode ser conceituada como a perda de participação do emprego e/ ou valor adicionado em relação a seus respectivos totais de forma permanente. Nesse caso, a desindustrialização será positiva se esse processo coincidir com um nível de renda per capita de país desenvolvido. Por outro lado, a desindustrialização será negativa se esse processo ocorrer antes que a economia alcance um nível de renda per capita de país desenvolvido.

No entanto esses conceitos foram definidos em nível de país, mas, como o propósito deste artigo será analisar a situação da indústria da região Nordeste, é preciso adequar esses conceitos ao nível regional e de estados. Para isso, será adotado o artigo de Silva (2017).

O processo de industrialização de uma região não ocorre de forma homogênea, de modo que, dentro de uma mesma região, é possível encontrar estados mais industrializados que outros. Os estados mais industrializados são denominados por Silva (2017) de estados avançados, e os menos industrializados, de atrasados. Portanto Silva (2017) considera que a incidência do processo de desindustrialização também não ocorre de forma igual. É possível a existência de um processo de desindustrialização em um estado e um processo de industrialização em outro simultaneamente, por isso que o autor prefere utilizar o temo (des)industrialização.

Assim, Silva (2017) mostra que, quando o aumento da participação da indústria dos estados atrasados ocorrer concomitantemente com a queda de participação da indústria de transformação do estado avançado, abrem-se três possibilidades de (des)industrialização regional: a estagnada, a regressiva e a progressiva.

A (des)industrialização regional estagnada ocorre quando se tem uma perda de participação da indústria de transformação no PIB regional, mas de modo que a participação da indústria regional no PIB industrial nacional permaneça sem grandes alterações. Esse conceito pode ser ampliado em uma versão positiva e outra negativa.

Quando esse processo ocorrer concomitante com o aumento de participação da indústria do estado atrasado no PIB industrial regional em detrimento da redução da participação industrial do estado avançado, se tem uma (des)industrialização regional estagnada positiva. Ou seja, é positiva porque ocorre um processo de desconcentração da atividade industrial na região. No entanto, para ser positiva, a estrutura produtiva de ambos os estados não precisa ser modificada, 
mas o deslocamento da produção de bens que eram produzidos no estado avançado para o estado atrasado já é suficiente para ser enquadrado nessa definição.

Porém, quando esse processo ocorrer concomitante à perda de participação da indústria dos estados atrasados no PIB industrial em detrimento do aumento da participação industrial do estado avançado, se tem uma (des)industrialização estagnada negativa. Ou seja, negativa porque ocorre um processo de concentração da atividade industrial no estado avançado e, ao mesmo tempo, o aprofundamento das vantagens comparativas de cada estado ${ }^{3}$. Nesse caso, as diferenças da estrutura produtiva dos estados não apenas são mantidas, mas aprofundadas.

No caso da (des)industrialização regional estagnada positiva, o estado avançado está se desindustrializando, e os estados atrasados estão se industrializando. Por outro lado, no caso da (des)industrialização regional estagnada negativa, tem-se o processo inverso.

A (des)industrialização regional regressiva ocorre quando se tem uma perda de participação da indústria regional no PIB total da região e no PIB industrial nacional.

Essa (des)industrialização regional regressiva pode ter um aspecto "positivo" se ocorrer acompanhada de um aumento de participação da indústria do estado atrasado no PIB da indústria regional pari passu com a redução da participação do estado avançado, de modo que isso implique um processo de desconcentração das atividades industriais na região.

E pode ter um aspecto negativo se a (des)industrialização regional regressiva for acompanhada de uma regressão da estrutura produtiva de ambos os estados que provoque o aprofundamento da concentração das atividades industriais no estado avançado.

Não obstante, nesse caso a estrutura produtiva do estado atrasado é orientada para a produção de bens (industriais ou não) nos quais possuem vantagens comparativas, enquanto a estrutura produtiva do estado industrializado é regredida em direção a produção de bens de baixo valor agregado, mas com valor agregado ainda superior ao dos estados atrasados.

Por outro lado, a (des)industrialização regional progressiva ocorre quando se tem uma redução da participação da indústria regional no PIB da região acompanhada de aumento de participação em relação ao PIB industrial nacional.

Nesse caso, ocorre um processo de desconcentração da produção ao nível nacional. No entanto, quando essa desconcentração implicar na desconcentração da produção industrial da região, tem-se um processo de (des)industrialização progressiva positiva. Caso contrário, se resultar na concentração da produção industrial no estado avançado, tem-se um processo de (des)industrialização progressiva negativa.

Já no caso da (des)industrialização regional progressiva "positiva", a estrutura produtiva do estado atrasado é orientada para a produção de bens com maior valor agregado decorrente de um processo de desconcentração das atividades industriais, proporcionado apenas pela transferência de atividades do estado avançado para o estado atrasado, que, diante das vantagens apresentadas por este último estado, têm estímulos para aumentar a produção.

Cabe observar que o conceito de (des)industrialização regressiva possui certa correspondência com o conceito de desindustrialização precoce enquanto que o conceito de desindustrialização progressiva tem semelhanças com o conceito de desindustrialização natural, visto anteriormente ao nível de país.

\footnotetext{
${ }^{3}$ Partindo da hipótese de que os estados atrasados e desenvolvidos apresentam, respectivamente, vantagens comparativas na produção de bens pouco e muito intensivo em capital.
} 
Destarte, definido os conceitos de desindustrialização regional, quais os principais fatores que podem levar uma região ao processo de desindustrialização? Segundo Silva (2017), essa resposta pode ser encontrada: i) no aumento da renda per capita, ii) no avanço tecnológico, iii) em uma política nacional/regional de desenvolvimento, iv) na uma tributação cumulativa, v) na "guerra fiscal", vi) na nova forma organizacional da produção manufatureira internacional; vii) na doença holandesa, viii) no acirramento da concorrência internacional.

A desindustrialização em termos regionais pode ocorrer quando o estado avançado alcança um grau elevado de renda per capita e uma situação próxima do pleno emprego. Nesse caso, há uma transferência de força de trabalho para o setor de serviços, tornando o custo de produção mais elevado na indústria de transformação. Com efeito, tende a ocorrer um processo de deslocamento das indústrias para outros estados (ou regiões) atrasados que apresentam um custo de mão de obra mais baixo. Desse modo, gera um processo de desindustrialização no estado avançado e de industrialização nos estados atrasados.

Quando o estado industrializado tem um avanço tecnológico, precisa se desfazer de suas máquinas e equipamentos obsoletos. Uma forma de se realizar isso é transferir toda ou parte dessa estrutura produtiva para os estados (ou regiões) atrasados. Nesse caso, ocorre um processo de desindustrialização no primeiro estado provocado pelo aumento da produtividade (proporcionado pelo avanço tecnológico) e, ao mesmo tempo, um processo de industrialização nos estados atrasados provocado pela transferência da estrutura produtiva obsoleta.

No caso de uma política nacional/regional de desenvolvimento no sentido de estimular a industrialização (seja de produção autônoma ou de complementaridade), o estado atrasado passa a obter um crescimento da produção industrial superior ao do estado avançado, de modo que sua industrialização pode significar a desindustrialização deste último estado. Isto é, quando a desindustrialização é tratada em termos regionais, ela pode ocorrer quando os estados que ainda não detêm um parque industrial, iniciam seu processo de industrialização, aumentando suas participações no PIB em relação ao estado já industrializado.

A forma de tributação pode levar também à desindustrialização de um estado. Quando a cobrança do imposto é realizada sobre a venda do bem durante todo o seu ciclo produtivo, a mesma empresa passa a produzir parte dos insumos que utiliza, evitando com isso a tributação cumulativa. Isto é, há uma tendência a interação vertical da produção pela empresa. Assim, o estado industrializado passa a produzir parte de seus insumos que antes adquiria do estado atrasado, de modo que se tem um processo de desindustrialização neste último.

Ainda dentro das questões tributárias, a desindustrialização pode ser provocada pela denominada "guerra fiscal". Na ausência de uma política nacional/regional de desenvolvimento, os estados podem fornecer isenções fiscais para que as indústrias se instalem em seus territórios ${ }^{4}$. Quando essas indústrias são atraídas de outros estados que se negaram a conceder os mesmos incentivos fiscais, a desindustrialização tende a ser apenas estadual e/ou regional uma vez que a indústria se desloca de um estado e/ou região para outro(a). Nesse caso, o estado que recebeu a indústria tende a obter um ganho de participação em detrimento da perda de participação do estado que perdeu a indústria, de modo que a desindustrialização nesse último estado tende a ser absoluta. Porém, quando a indústria pretende abrir uma nova empresa, ceteris paribus, o estado que fornecer maiores incentivos fiscais tende a aumentar a sua participação no PIB, enquanto

\footnotetext{
${ }^{4}$ Para uma análise da guerra fiscal como alternativa as políticas nacionais de desenvolvimento, vide Prado (2000).
} 
os demais estados tendem a ter suas participações reduzidas. No entanto a desindustrialização será apenas relativa ${ }^{5}$.

No que diz respeito a fatores externos, a desindustrialização regional pode ser o resultado da nova forma organizacional da produção manufatureira internacional que ocorre através de cadeias globais de valor. Nesse caso, como o objetivo dos investimentos direto estrangeiros (IDE) é se apropriar de parte do mercado doméstico, grande parte do IDE é direcionada para a fase final do processo produtivo, no qual as empresas são apenas maquiladoras, isto é, montadoras de peças importadas 6 . Com isso, o estado avançado ao ser o principal receptor dos IDE acaba quebrando as relações produtivas com os estados atrasados, de modo que tais estados passam a apresentar um processo de desindustrialização não apenas relativo, mas também absoluto.

De modo geral, a nova forma organizacional da produção manufatureira internacional tende a diminuir a dinâmica do comércio interestadual/regional reduzindo o efeito multiplicador da produção industrial no país, de modo que esse processo modifica o comércio interestadual, acirra a guerra fiscal e abala a integração regional da indústria de transformação no país.

A "doença holandesa" (derivada da descoberta de recursos naturais, da valorização dos preços das commodities ou da maior abertura financeira), que se manifesta via sobreapreciação real da taxa de câmbio, também é outro fator que pode provocar um processo de desindustrialização regional. Essa sobreapreciação cambial, ao reduzir a competividade da indústria do estado avançado, tanto nos mercados doméstico quanto externos, gera a redução da produção industrial. Sendo a produção do estado atrasado complementar a produção do estado industrializado, ocorre simultaneamente a redução da produção industrial do estado atrasado. Ou seja, ambos os estados passam por um processo de desindustrialização.

Um aumento da concorrência internacional também pode levar a um processo de desindustrialização de ambos os estados. Nesse caso, na ausência de políticas protecionistas a favor da indústria doméstica, um forte concorrente pode gerar a substituição do consumo de bens domésticos por bens importados e, portanto, provocar a redução da produção industrial doméstica no estado avançado e, consequentemente, do estado atrasado.

Não obstante, a doença holandesa e o aumento da concorrência internacional podem ser menos prejudicial à região pouco industrializada em relação a uma região com grau mais elevado de industrialização, uma vez que, para aumentar a competitividade de seus produtos, as indústrias nas regiões desenvolvidas podem resolver transferir parte de sua produção para as regiões pouco industrializadas com o objetivo de aproveitar o baixo custo da mão de obra local.

De posse dos conceitos de desindustrialização e suas causas, o objetivo da próxima seção será observar a evolução da indústria de transformação da região Nordeste no período 20022014 tentando identificar um possível processo de (des)industrialização na região.

\footnotetext{
${ }^{5}$ No primeiro caso, se o deslocamento das empresas ocorrer entre estados de uma mesma região e se as estruturas produtivas forem idênticas, o efeito da guerra fiscal sobre o PIB industrial da região tende a ser nulo. Por outro lado, no segundo caso, a criação de nova empresa tende a aumentar o PIB industrial da região.

${ }^{6}$ Segundo Sampaio (2015), esse processo é diferente do de substituição de importações, uma vez que a decisão de agregação de valor dos bens produzidos no país é determinada pelas empresas internacionais. Em outras palavras, trata-se de uma inserção "subordinada" nas cadeias globais de valor.
} 


\section{A DESINDUSTRIALIZAÇÃO NA REGIÃO NORDESTE}

A divulgação dos dados das contas nacionais no final dos anos 1950 mostrou a concentração da atividade industrial e da renda na região Sudeste. Com efeito, as demais regiões passaram a exigir uma política regional de desenvolvimento. Como resultado, foi criado no Nordeste a Superintendência do Desenvolvimento do Nordeste (Sudene), cujo objetivo era o de industrializar a região.

A política adotada pela Sudene seguiu a linha cepalina de industrialização por substituição de importações, que estava em curso desde os aos 1930. Na perspectiva de Celso Furtado (dirigente da Sudene), a indústria deveria ser o motor do crescimento econômico nordestino, através de um centro autônomo de expansão manufatureira. Para isso, foram utilizados os incentivos fiscais conhecidos como 34/18 FINOR.

Inicialmente, o objetivo era estimular a indústria de base e indústrias que se utilizavam em seu processo produtivo de insumos locais. Com isso, as indústrias nordestinas poderiam competir com as indústrias da região Sudeste. Além disso, dados os efeitos de encadeamento da indústria de transformação, esperava-se a redução da taxa de desemprego no Nordeste.

Não obstante, Araújo (2000) afirma que os resultados da Sudene foram outros. A indústria nordestina passou por transformações, uma vez que o parque industrial foi modernizado e a produção diversificada. Porém esse processo foi liderado pelas empresas que migraram do Sudeste para o Nordeste estimuladas pelos incentivos fiscais e pelo baixo custo da mão de obra nordestina, de modo que as indústrias nordestinas tradicionais foram sucateadas, ficando com menos de 30\% dos recursos do 34/18 FINOR.

Segundo Araújo (2000), isso ocorreu porque o Nordeste se caracteriza por relações de dependência e complementariedade. Dependência em relação a crédito, mercado, insumos e equipamentos da região Sudeste. Complementariedade por causa da sua função de fornecedor de insumos para a indústria do Sudeste. Devido a essas duas características, os efeitos e encadeamentos e de transbordamentos foram significativamente reduzidos. Apesar disso, nesse período, a indústria de transformação do Nordeste aumentou sua participação no PIB industrial nacional. Segundo Furtado, poucas regiões conheceram um processo de industrialização tão intenso por duas décadas como o apresentado no Nordeste.

Na década de 1970, período do milagre econômico, o forte crescimento proporcionado pelas políticas de Estado e a maior integralização econômica entre as regiões permitiram a continuidade do processo de industrialização da região Nordeste.

Nos anos 1980, as políticas de estímulos fiscais foram substituídas pelos incentivos às exportações, uma vez que era necessário gerar divisas para o pagamento da dívida externa. Com efeito, houve um forte crescimento das exportações dos estados no Nordeste, o que contribuiu para uma mudança da composição da pauta de exportação da região, onde os bens intermediários ganharam mais espaços. Isso ocorreu porque a indústria instalada no Nordeste era especializada na produção de bens intermediários, setor pouco afetado pela crise dos anos 1980. Desse modo, segundo Silva e Teixeira (2014), a desconcentração da renda e da atividade industrial no período ocorria via ajuste da economia brasileira às condições internacionais, e não através do investimento industrial. No entanto, para Cano (1998), essa desconcentração é meramente estatística, dado que a crise afetou o Sudeste de forma mais forte que o Nordeste, de modo que a participação industrial da região periférica aumentou devido à queda significativa da produção industrial da região avançada. 
Na década de 1990, as políticas neoliberais entravam em cena, as políticas regionais de desenvolvimento foram substituídas pelas políticas de mercado. Com efeito, as políticas neoliberais dinamizaram ainda mais as regiões competitivas, uma vez que a lógica do mercado é a eficiência competitiva, restando para os estados pouco competitivos a "guerra fiscal". Por outro lado, a abertura comercial combinada com a implementação e valorização do Real provocou a perda de competividade dos produtos industriais da região Sudeste. Com efeito, os empresários tenderam a retardar novos investimentos, gerando perda de participação tanto em termos de emprego quanto de produção. Ou seja, iniciava-se o processo de desindustrialização. Como a dinâmica do Nordeste está de certa forma ligada à dinâmica do Sudeste, o mesmo ocorreu nos estados nordestinos.

Porém, nos anos 2000, houve um retorno das políticas regionais de desenvolvimento promovidas pelo Estado. Mas será que essas políticas provocaram a desconcentração da produção industrial na região Nordeste? Isso é o que se pretende verificar a partir de agora.

A análise dos indicadores clássicos da desindustrialização para o Brasil mostra uma perda de 2,3 p.p. para o emprego entre 2007 e 2014 e uma perda de 5,8 p.p. em relação à produção da indústria de transformação entre 2004 e 2014. Portanto a economia brasileira apresentava um processo de desindustrialização mais acentuado em termos de produção do que de emprego.

Todavia, a região Nordeste no agregado parece ter influenciado pouco nesse processo ao nível nacional, uma vez que a participação da produção e do emprego da indústria de transformação nordestina no emprego total do país e no PIB permaneceu praticamente estável no período em foco como pode ser observado nas figuras 1 e 2 a seguir.

Figura 1- Participação do Emprego da Indústria de Transformação da Região Nordeste, do Brasil e das Demais Regiões no Emprego Total do Brasil: 2002-2014

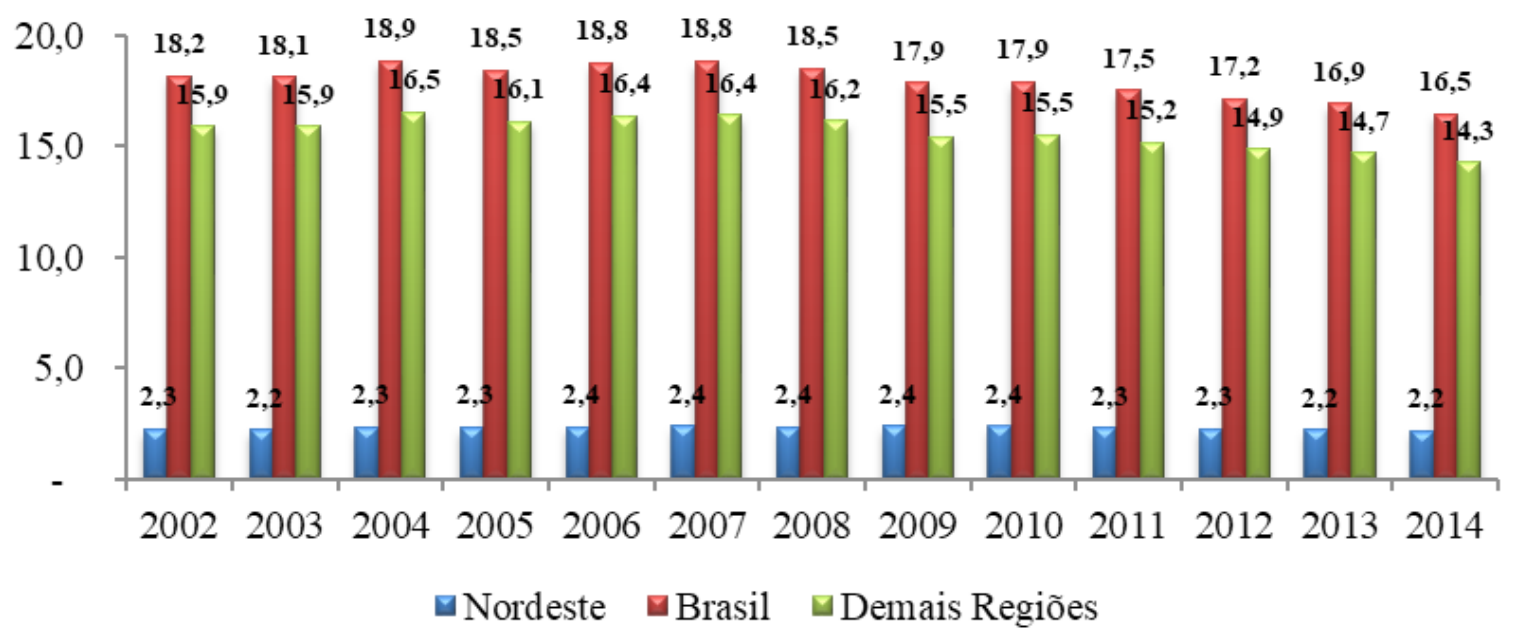

Fonte: Elaboração própria a partir dos dados da Relação Anual de Informações Sociais (RAIS, 2017).

Não obstante, esse tipo de análise apenas pelos indicadores clássicos da desindustrialização mostra a importância da região Nordeste no processo de desindustrialização nacional, mas omite as modificações na estrutura produtiva nordestina, bem como nos seus estados. Dessa forma, esses indicadores são insuficientes para se chegar a qualquer conclusão sobre a evolução da indústria de transformação no Nordeste e em seus estados, sendo necessário utilizar os indicadores desenvolvidos por Silva (2017). 
Figura 2 - Participação da Produção da Indústria de Transformação da Região Nordeste, do Brasil e das Demais Regiões no PIB do Brasil: 2002-2014

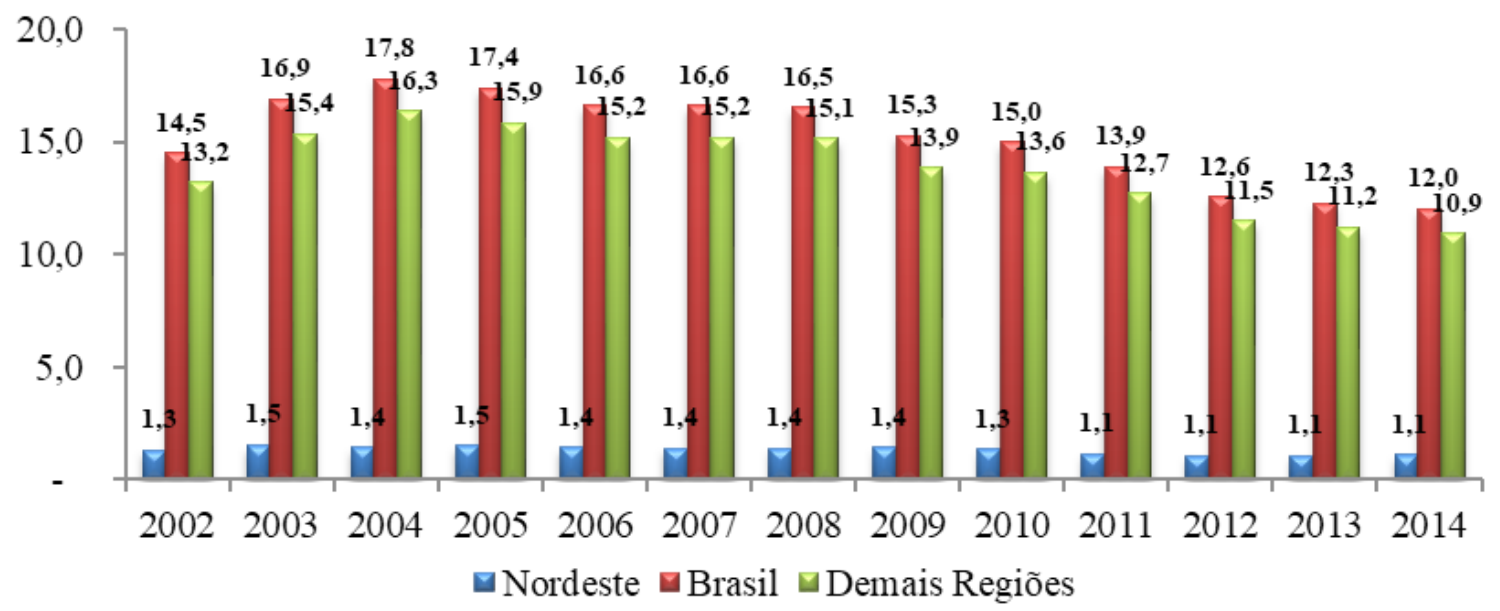

Fonte: Elaboração própria a partir dos dados das Contas Regionais do Instituto Brasileiro de Geografia e Estatística (IBGE, 2017).

Figura 3 - Participação da Indústria de Transformação da Região Nordeste no PIB e no Emprego Total da Região Nordeste: 2002-2014

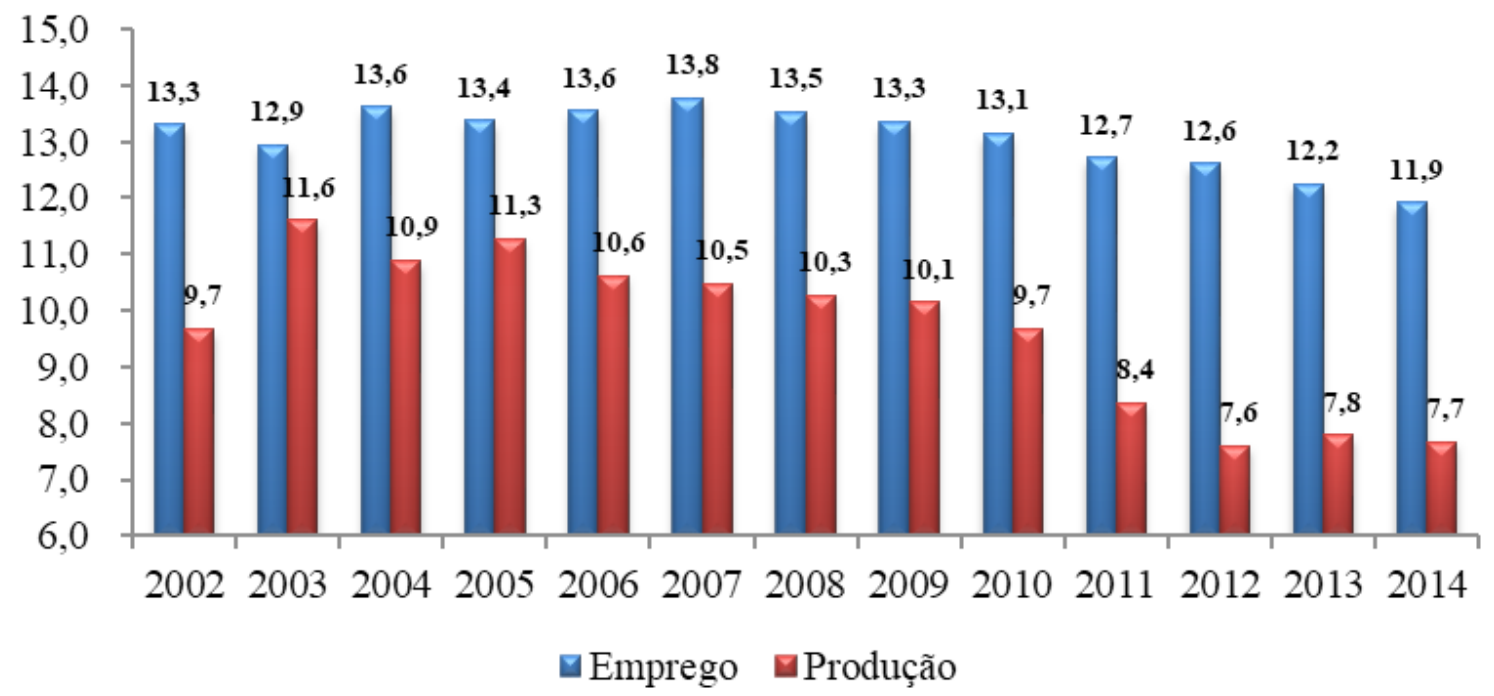

Fonte: Elaboração própria a partir dos dados das Contas Nacionais (IBGE) e da RAIS (2017).

A figura 3 mostra a evolução da participação do emprego e da produção da indústria de transformação na região Nordeste em relação ao PIB nordestino e, ao contrário do observado nas figuras 1 e 2, tem-se uma perda de participação do emprego de 1,9 p.p. entre 2007 e 2014 e de 3,9 p.p. em relação à produção industrial entre 2003 e 2014. Com efeito, observa-se um processo de desindustrialização na região Nordeste no período em estudo, porém esse processo se apresenta mais acentuado em termos de produção do que de emprego. Similar ao movimento da indústria nacional. Mas em quais estados esse processo tem sido mais grave? As tabelas 1 e 2 mostram os dados da figura 3 de forma desagregada por estado.

Por exemplo, no ano de 2002, a participação da indústria de transformação nordestina no PIB total do Nordeste (Tabela 1) era de 9,7\%, dos quais o estado da Bahia foi responsável por 2,8 
p.p. Do mesmo modo, para os dados referentes ao emprego na tabela 2. Com isso, é possível identificar onde está localizado o processo de desindustrialização da região Nordeste.

Dito isto, observa-se que a perda de participação de 2,0 p.p. da produção que a indústria nordestina teve entre 2002 e 2014 se concentrou nos estados da Bahia e Ceará, ambos tiveram uma perda de 0,5 p.p. O estado de alagoas foi o terceiro estado que apresentou maior perda, 0,3 p.p. enquanto o Rio Grande do Norte e Sergipe tiveram uma perda de 0,2 p.p. Os demais estados apresentaram uma perda de 0,1 p.p. cada um.

Tabela 1 - Participação da produção da indústria de transformação dos estados no PIB da região Nordeste: 2002-2014

\begin{tabular}{lccccccccccccc}
\hline & $\mathbf{2 0 0 2}$ & $\mathbf{2 0 0 3}$ & $\mathbf{2 0 0 4}$ & $\mathbf{2 0 0 5}$ & $\mathbf{2 0 0 6}$ & $\mathbf{2 0 0 7}$ & $\mathbf{2 0 0 8}$ & $\mathbf{2 0 0 9}$ & $\mathbf{2 0 1 0}$ & $\mathbf{2 0 1 1}$ & $\mathbf{2 0 1 2}$ & $\mathbf{2 0 1 3}$ & $\mathbf{2 0 1 4}$ \\
Alagoas & 0,7 & 0,8 & 0,8 & 0,7 & 0,6 & 0,6 & 0,6 & 0,4 & 0,4 & 0,6 & 0,5 & 0,4 & 0,4 \\
Bahia & 2,8 & 3,6 & 3,6 & 4,2 & 3,4 & 3,3 & 3,1 & 4,0 & 3,7 & 2,5 & 1,9 & 2,0 & 2,3 \\
Ceará & 1,9 & 1,9 & 2,0 & 1,9 & 1,9 & 1,8 & 1,9 & 1,9 & 1,7 & 1,6 & 1,5 & 1,6 & 1,4 \\
Maranhão & 0,6 & 0,9 & 0,7 & 0,7 & 1,0 & 0,8 & 0,7 & 0,4 & 0,3 & 0,4 & 0,5 & 0,5 & 0,5 \\
Paraíba & 0,6 & 0,9 & 0,7 & 0,7 & 0,7 & 0,7 & 0,7 & 0,7 & 0,6 & 0,6 & 0,5 & 0,5 & 0,5 \\
Pernambuco & 1,8 & 2,1 & 1,9 & 1,8 & 1,8 & 1,9 & 1,9 & 1,8 & 1,8 & 1,7 & 1,9 & 2,0 & 1,7 \\
Piauí & 0,2 & 0,3 & 0,2 & 0,2 & 0,3 & 0,2 & 0,3 & 0,3 & 0,2 & 0,2 & 0,2 & 0,2 & 0,2 \\
Rio Grande do Norte & 0,5 & 0,5 & 0,4 & 0,5 & 0,6 & 0,7 & 0,7 & 0,4 & 0,5 & 0,4 & 0,4 & 0,3 & 0,3 \\
Sergipe & 0,5 & 0,6 & 0,5 & 0,5 & 0,5 & 0,5 & 0,4 & 0,4 & 0,3 & 0,3 & 0,3 & 0,3 & 0,3 \\
\hline Nordeste & $\mathbf{9 , 7}$ & $\mathbf{1 1 , 6}$ & $\mathbf{1 0 , 9}$ & $\mathbf{1 1 , 3}$ & $\mathbf{1 0 , 6}$ & $\mathbf{1 0 , 5}$ & $\mathbf{1 0 , 3}$ & $\mathbf{1 0 , 1}$ & $\mathbf{9 , 7}$ & $\mathbf{8 , 4}$ & $\mathbf{7 , 6}$ & $\mathbf{7 , 8}$ & $\mathbf{7 , 7}$ \\
\hline
\end{tabular}

Fonte: Elaboração própria a partir dos dados das Contas Nacionais do IBGE (2017).

Pela ótica do emprego, da perda de 1,4 p.p. da indústria nordestina entre 2002 e 2014, quase metade foi derivada da indústria do estado de Alagoas. O Ceará e o Rio Grande do Norte apresentaram uma perda de 0,3 p.p. A soma das perdas de participações dos estados da Paraíba, Pernambuco e Piauí totalizam cerca de 0,2 p.p. Por outro lado, os demais estados apresentaram leve ganho de participação entre 2002 e 2014.

Se for considerada a participação dos estados mais industrializados, observa-se que, dos 9,7\% de participação da produção industrial nordestina no PIB do Nordeste, 6,5 p.p. pertencem aos estados da Bahia, Ceará e Pernambuco, restando apenas 3,2 p.p. para os outros seis estados. Em 2014, a participação da indústria nordestina diminuiu para 7,7\% no PIB regional; desse percentual, 5,4 p.p. pertencem aos três estados mais ricos, e 2,3 p.p. aos demais estados da região. Na ótica do emprego, os três estados detinham 8,4 p.p. de um total de 13,3\% em 2002 da indústria do Nordeste e passou para 8,0 p.p. em 2014 de um total de 11,9\%. Por outro lado, os demais estados passaram de 4,9 p.p. em 2002 para 3,9 p.p. em 2014. Portanto trata-se de um processo de desindustrialização generalizado entre todos os estados da região nordeste. 
Tabela 2- Participação do emprego da indústria de transformação dos estados no emprego total da região Nordeste: 2002-2014.

\begin{tabular}{lccccccccccccc}
\hline & $\mathbf{2 0 0 2}$ & $\mathbf{2 0 0 3}$ & $\mathbf{2 0 0 4}$ & $\mathbf{2 0 0 5}$ & $\mathbf{2 0 0 6}$ & $\mathbf{2 0 0 7}$ & $\mathbf{2 0 0 8}$ & $\mathbf{2 0 0 9}$ & $\mathbf{2 0 1 0}$ & $\mathbf{2 0 1 1}$ & $\mathbf{2 0 1 2}$ & $\mathbf{2 0 1 3}$ & $\mathbf{2 0 1 4}$ \\
Alagoas & 1,6 & 1,6 & 1,8 & 1,7 & 1,6 & 1,6 & 1,5 & 1,4 & 1,3 & 1,3 & 1,2 & 1,0 & 0,9 \\
Bahia & 2,4 & 2,5 & 2,6 & 2,7 & 2,7 & 2,8 & 2,8 & 2,8 & 2,8 & 2,8 & 2,7 & 2,6 & 2,5 \\
Ceará & 3,2 & 3,2 & 3,3 & 3,1 & 3,2 & 3,2 & 3,1 & 3,2 & 3,1 & 3,0 & 3,0 & 3,0 & 2,9 \\
Maranhão & 0,4 & 0,4 & 0,4 & 0,4 & 0,5 & 0,5 & 0,5 & 0,4 & 0,4 & 0,5 & 0,5 & 0,5 & 0,5 \\
Paraíba & 1,0 & 0,9 & 0,9 & 1,0 & 1,0 & 1,0 & 1,0 & 0,9 & 0,9 & 0,9 & 0,9 & 0,9 & 0,9 \\
Pernambuco & 2,7 & 2,5 & 2,7 & 2,8 & 2,8 & 2,9 & 2,9 & 2,9 & 2,7 & 2,7 & 2,7 & 2,7 & 2,6 \\
Piauí & 0,4 & 0,4 & 0,4 & 0,4 & 0,4 & 0,4 & 0,3 & 0,3 & 0,3 & 0,3 & 0,3 & 0,3 & 0,3 \\
Rio Grande do Norte & 1,0 & 0,9 & 0,9 & 0,9 & 0,9 & 1,0 & 1,0 & 0,9 & 0,9 & 0,8 & 0,8 & 0,7 & 0,7 \\
Sergipe & 0,5 & 0,5 & 0,5 & 0,5 & 0,5 & 0,5 & 0,5 & 0,5 & 0,5 & 0,5 & 0,5 & 0,5 & 0,5 \\
\hline Nordeste & $\mathbf{1 3 , 3}$ & $\mathbf{1 2 , 9}$ & $\mathbf{1 3 , 6}$ & $\mathbf{1 3 , 4}$ & $\mathbf{1 3 , 6}$ & $\mathbf{1 3 , 8}$ & $\mathbf{1 3 , 5}$ & $\mathbf{1 3 , 3}$ & $\mathbf{1 3 , 1}$ & $\mathbf{1 2 , 7}$ & $\mathbf{1 2 , 6}$ & $\mathbf{1 2 , 2}$ & $\mathbf{1 1 , 9}$ \\
\hline
\end{tabular}

Fonte: Elaboração própria a partir dos dados da RAIS (2017).

Mas qual o tipo de desindustrialização? Estagnada, regressiva ou positiva? Para saber isso, será preciso analisar a trajetória da indústria de transformação nordestina em relação à brasileira, o que pode ser visto na figura 4.

Figura 4 - Participação da produção e do emprego da indústria de transformação da região Sul na produção e emprego da indústria de transformação do Brasil: 2002-2014

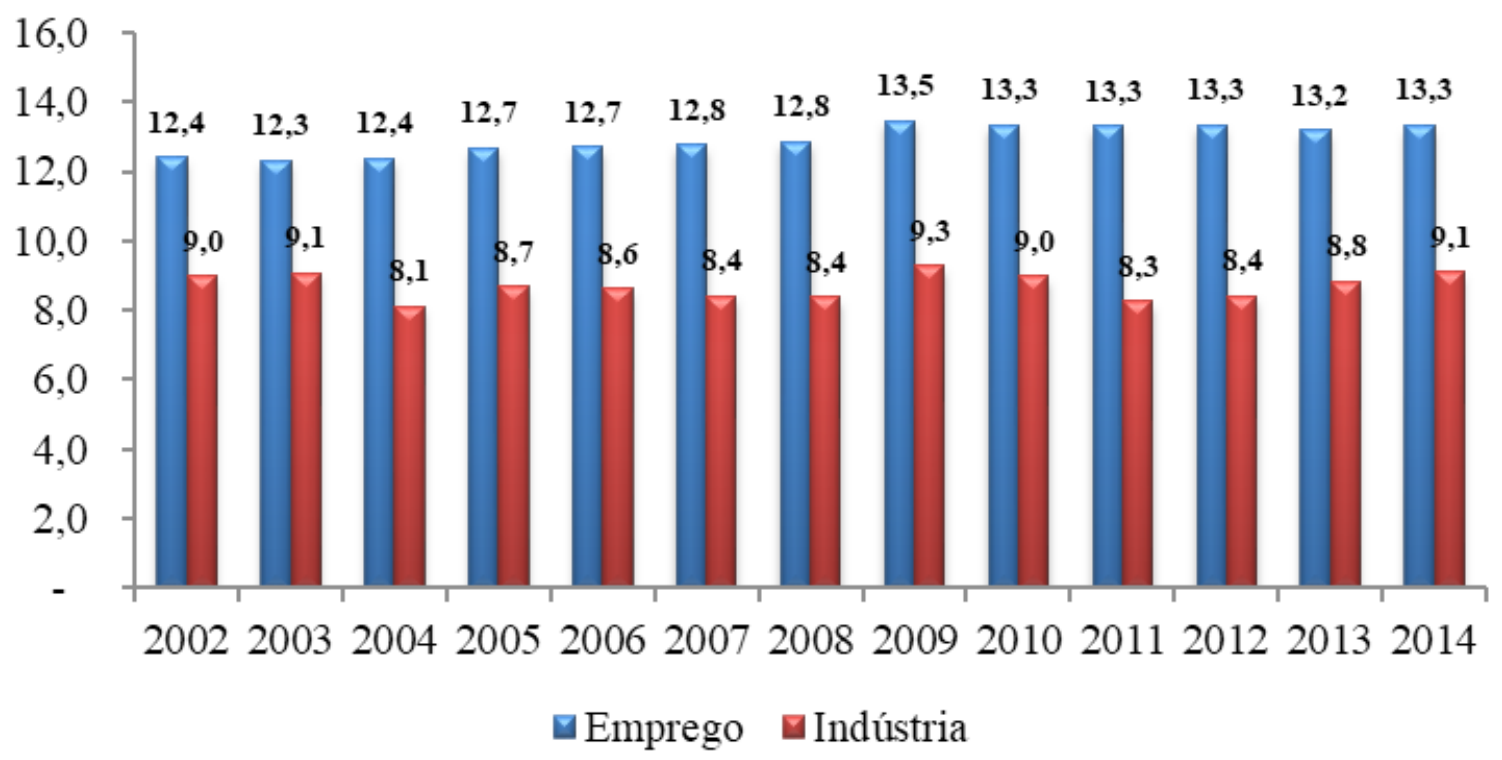

Fonte: Elaboração própria a partir dos dados das Contas Nacionais (IBGE) e da RAIS (2017).

A participação da indústria de transformação da região Nordeste na produção da indústria nacional apresentou uma média de 8,7\% entre 2002 e 2014. Porém é importante destacar dois períodos. Entre 2003 e 2004, quando a participação da indústria de transformação caiu 1 p.p., e em 2008-2009, quando ocorreu um aumento de 0,9 p.p.

Em termos de emprego, a participação média no período foi de 12,9\%, mas se manteve estável em 13,3\% no período pós-2010. Essa trajetória do emprego pode ser explicada pela busca de aumento de competitividade da indústria de outras regiões com um grau elevado de 
industrialização, como o Sudeste. Desde a década de 1990, quando ocorreu a abertura comercial, as empresas têm realizado uma realocação de empregos com o objetivo de reduzir custos e aumentar a competividade. Essa realocação foi intensificada devido à sobreapreciação da taxa de câmbio no período em foco. Com efeito, os estados do Nordeste foram beneficiados com o aumento do emprego, uma vez que a força de trabalho na região ainda é relativamente barata em comparação com a região Sudeste.

Contudo, embora a região Nordeste tenha obtido um ganho de participação da produção industrial em relação à indústria de transformação do Brasil no período pós-2011 e do emprego entre 2013 e 2014, esse aumento é insuficiente para caracterizar o processo de desindustrialização na região Nordeste como progressiva, mas suficiente para enquadrá-la como estagnada.

Todavia, será que esse processo de desindustrialização na regional Nordeste foi acompanhado de uma desconcentração da produção e do emprego industrial entre os estados da região em foco? Isto é, a desindustrialização regional em voga no Nordeste é do tipo positiva ou negativa? Para encontrar essa resposta, é preciso analisar a distribuição da produção e do emprego da indústria de transformação entre os diversos estados da região Nordeste, como pode ser observado nas tabelas 3 e 4.

Tabela 3 - Distribuição da produção da indústria de transformação dos estados da região Nordeste: 2002-2014

\begin{tabular}{lcccccccccccccc}
\hline & $\mathbf{2 0 0 2}$ & $\mathbf{2 0 0 3}$ & $\mathbf{2 0 0 4}$ & $\mathbf{2 0 0 5}$ & $\mathbf{2 0 0 6}$ & $\mathbf{2 0 0 7}$ & $\mathbf{2 0 0 8}$ & $\mathbf{2 0 0 9}$ & $\mathbf{2 0 1 0}$ & $\mathbf{2 0 1 1}$ & $\mathbf{2 0 1 2}$ & $\mathbf{2 0 1 3}$ & $\mathbf{2 0 1 4}$ \\
Alagoas & 7,0 & 7,1 & 7,4 & 5,9 & 5,6 & 5,9 & 5,5 & 3,7 & 4,5 & 7,6 & 6,3 & 4,7 & 4,6 \\
Bahia & 29,5 & 30,8 & 32,9 & 37,0 & 32,3 & 31,6 & 30,3 & 39,9 & 38,4 & 30,3 & 24,4 & 26,2 & 29,3 \\
Ceará & 19,4 & 16,5 & 18,5 & 16,5 & 17,5 & 17,3 & 18,8 & 18,5 & 17,5 & 19,0 & 19,1 & 19,9 & 18,7 \\
Maranhão & 6,4 & 7,9 & 6,6 & 6,5 & 9,1 & 8,0 & 6,6 & 3,7 & 3,4 & 4,5 & 6,5 & 6,2 & 7,0 \\
Paraíba & 6,6 & 7,5 & 6,6 & 6,5 & 6,4 & 6,3 & 6,8 & 6,6 & 6,2 & 6,8 & 7,2 & 6,9 & 6,6 \\
Pernambuco & 18,1 & 18,3 & 17,3 & 16,2 & 17,0 & 17,8 & 18,7 & 17,6 & 18,8 & 19,8 & 24,8 & 25,6 & 22,7 \\
Piauí & 2,3 & 2,3 & 1,9 & 2,2 & 2,4 & 2,2 & 2,5 & 2,6 & 2,3 & 2,6 & 2,8 & 2,0 & 3,0 \\
Rio Grande do Norte & 5,2 & 4,4 & 4,0 & 4,7 & 5,4 & 6,6 & 6,5 & 3,9 & 5,5 & 5,2 & 4,8 & 4,0 & 3,9 \\
Sergipe & 5,4 & 5,2 & 4,8 & 4,5 & 4,3 & 4,4 & 4,3 & 3,5 & 3,3 & 4,1 & 4,0 & 4,4 & 4,2 \\
\hline
\end{tabular}

Fonte: Elaboração própria a partir dos dados das Contas Nacionais do IBGE (2017).

Para realizar a análise dos estados, será necessário realizar uma adaptação aos conceitos de Silva (2017). Como a Bahia, Ceará e Pernambuco apresentam níveis mais elevados de industrialização dentre todos os estados da região Nordeste, esses estados serão considerados avançados, e os demais estados considerados atrasados.

No que diz respeito à participação dos estados na produção industrial do Nordeste (Tabela 3), observa-se uma concentração em três estados: Bahia, Pernambuco e Ceará. A Bahia, mesmo com a perda de participação na última década, ainda detém cerca 30\% da produção industrial do Nordeste em 2014. O estado do Ceará apresentou uma trajetória relativamente instável, de modo que, em 2013, possuía uma participação maior que a apresentada em 2002, mas, em 2014, esse percentual caiu para 18,7\%. Já Pernambuco apresentou ganho expressivo, sobretudo, entre 2010 e 2013. O estado passou de 18,8\% da produção industrial do Nordeste, em 2010, para 25,6\% em 2013. Entretanto teve uma queda de quase 3,0 p.p. em 2014. 
Em relação aos demais estados, Alagoas, Rio Grande do Norte e Sergipe apresentaram significativas reduções de participação no período em estudo. Alagoas teve sucessivas quedas até 2007, quando iniciou uma recuperação que foi interrompida em 2012, possuindo apenas 4,6\% de toda a produção industrial do Nordeste. O Rio Grande do Norte passou de 5,2\% da produção industrial em 2002 para 3,9\% em 2014. E Sergipe passou de 5,4\% para 4,2\% no mesmo período.

Por outro lado, Maranhão e Piauí apresentaram um aumento de participação na produção industrial regional. Ou seja, enquanto Alagoas, Rio Grande do Norte e Sergipe estão se desindustrializando, Maranhão e Sergipe estão em processo de industrialização.

No entanto a produção industrial continua muito concentrada nos estados avançados, de modo que é possível identificar, no período em foco, dois tipos de desindustrialização estagnada: i) estagnada negativa entre 2002 e 2009, quando a soma das participações dos estados da Bahia, Ceará e Pernambuco passou de 67\% para 76\%; ii) estagnada positiva entre 2009 e 2014, quando a soma das participações dos estados avançados caiu para $70 \%$.

Tabela 4 - Distribuição do emprego da indústria de transformação dos estados da região Nordeste: 2002-2014

\begin{tabular}{lcccccccccccccc}
\hline & $\mathbf{2 0 0 2}$ & $\mathbf{2 0 0 3}$ & $\mathbf{2 0 0 4}$ & $\mathbf{2 0 0 5}$ & $\mathbf{2 0 0 6}$ & $\mathbf{2 0 0 7}$ & $\mathbf{2 0 0 8}$ & $\mathbf{2 0 0 9}$ & $\mathbf{2 0 1 0}$ & $\mathbf{2 0 1 1}$ & $\mathbf{2 0 1 2}$ & $\mathbf{2 0 1 3}$ & $\mathbf{2 0 1 4}$ \\
Alagoas & 11,9 & 12,2 & 12,9 & 12,4 & 12,1 & 11,4 & 11,1 & 10,6 & 10,0 & 9,9 & 9,5 & 8,5 & 7,8 \\
Bahia & 18,3 & 19,3 & 19,4 & 19,9 & 20,0 & 20,4 & 20,4 & 20,7 & 21,3 & 21,6 & 21,1 & 21,0 & 21,1 \\
Ceará & 23,9 & 24,9 & 24,1 & 23,3 & 23,3 & 23,0 & 22,9 & 23,9 & 23,9 & 23,3 & 23,8 & 24,1 & 24,3 \\
Maranhão & 3,3 & 3,4 & 3,2 & 3,1 & 3,5 & 3,7 & 3,8 & 3,3 & 3,4 & 3,6 & 3,8 & 4,0 & 3,8 \\
Paraíba & 7,5 & 6,9 & 6,9 & 7,1 & 7,0 & 7,3 & 7,1 & 6,9 & 7,1 & 7,2 & 7,4 & 7,4 & 7,5 \\
Pernambuco & 20,6 & 19,6 & 20,2 & 20,6 & 20,9 & 20,8 & 21,3 & 21,4 & 20,6 & 21,2 & 21,3 & 21,9 & 22,1 \\
Piauí & 2,9 & 2,9 & 2,7 & 2,7 & 2,7 & 2,6 & 2,5 & 2,6 & 2,6 & 2,6 & 2,6 & 2,7 & 2,8 \\
Rio Grande do Norte & 7,7 & 6,8 & 6,8 & 6,8 & 6,7 & 7,1 & 7,2 & 6,9 & 7,1 & 6,4 & 6,2 & 6,1 & 6,1 \\
Sergipe & 3,9 & 3,9 & 3,8 & 4,0 & 3,8 & 3,7 & 3,6 & 3,7 & 3,9 & 4,2 & 4,3 & 4,3 & 4,4 \\
\hline
\end{tabular}

Fonte: Elaboração própria a partir dos dados da RAIS (2017).

Em termos de emprego, observa-se que a Bahia não detém a maior participação, ficando atrás do Ceará. No entanto, do mesmo modo que a produção, o emprego industrial na região Nordeste continua concentrado nos mesmos três estados, isto é, Ceará, Bahia e Pernambuco. Em 2002, esses três estados concentravam quase 63\% do emprego industrial. Não obstante esse percentual aumentou para 67,5\% em 2014. Esse ganho de participação foi o resultado das políticas de isenções fiscais realizadas por esses estados no período em análise, para atrair empresas do ramo calçadista, têxtil e automobilístico. Só a Bahia, por exemplo, foi responsável por cerca de 30\% dos incentivos da Sudene em 2014.

No entanto outros estados perderam participação, como é o caso do Rio Grande do Norte e Alagoas. A perda de participação do emprego industrial no Rio Grande do Norte pode ser explicada pela desaceleração da indústria salineira e pelo fim dos incentivos fiscais concedidos às empresas de bebidas, têxtil e calçadista. Já o estado de Alagoas nos últimos três anos da série em análise, apresentou uma perda não apenas relativa, mas também absoluta. Como os bens produzidos em Alagoas são intensivos em mão de obra (indústria da cana de açúcar e de alimentos e bebidas), a redução da produção (tabela 3), isso refletiu na queda do emprego industrial (Tabela 4), porém não na mesma proporção. 
Diversos fatores contribuíram para essa perda de participação do emprego. Primeiro, com a perda de competitividade do etanol, foram desativadas quatro importantes usinas, o que equivale a cerca de no mínimo dez mil empregos a menos na indústria alagoana. Segundo, a combinação da seca com os preços praticados pelo governo federal, com as empresas descapitalizadas e sem acesso a novas linhas de crédito, gerou como consequência: i) uma variação negativa da produção nos últimos anos do período em análise e na demissão de trabalhadores; ii) endividamento das empresas; iii) redução das receitas do estado de Alagoas. Terceiro, sendo a economia alagoana muito dependente do setor sucroalcooleiro, os demais setores foram afetados, gerando também o fechamento de outras empresas ligadas ao setor sucroalcooleiro e, consequentemente, a redução de empregos industriais. Quarto, as usinas em todo o país e, portanto, em Alagoas têm buscado se mecanizar, ou seja, substituir o homem pela máquina com o objetivo de se tornar mais produtiva. Isso explica o descompasso entre a taxa de participação da produção e do emprego na indústria de Alagoas. Com efeito, a participação do emprego no estado diminuiu. Por fim, sendo a maior parte dessa produção direcionada para o mercado interno, a desaceleração da economia brasileira pós-2010 também contribuiu para a perda de importância da indústria alagoana.

Considerando a região Nordeste e utilizando os conceitos desenvolvidos por Silva (2017), pode-se concluir que a região Nordeste passa por um processo de desindustrialização regional estagnada negativo em termos de produção, uma vez que, apesar da desconcentração no período pós-2009, a soma das participações dos estados avançados em 2014 é maior que o valor apresentado em 2002. No mesmo sentido, a soma das participações dos estados avançados em termos de emprego no ano de 2014 é maior que o valor apresentado em 2002, de modo que tanto a produção quanto o emprego se tornaram mais concentrado no período em estudo.

\section{CONSIDERAÇÕES FINAIS}

A indústria de transformação nacional tem apresentado uma participação menor a cada ano, tendo uma participação de 12\% em 2014 no PIB. Dez anos antes, essa participação era superior a 18\%, ou seja, uma perda de mais de 6,0 p.p. Destarte, esse processo tem recebido ênfase e nível agregado dentro do debate acadêmico, sendo ainda muito pouco debatida a desindustrialização nas regiões brasileiras. Com o objetivo de ampliar essa discussão, este artigo teve por objetivo observar se há um processo de desindustrialização na região Nordeste.

Para alcançar esse objetivo, primeiro foi realizada uma discussão teórica acerca do conceito de desindustrialização, destacando desde as primeiras definições até versões mais contemporâneas.

A segunda seção deste artigo procurou primeiro identificar o processo de desindustrialização na região Nordeste. Nesse sentido, foi observado que a participação do Nordeste em termos de produção e emprego foi relativamente estável no período 2002-2014 em relação ao PIB nacional. Ou seja, quando utilizado os indicadores clássicos da desindustrialização. Contudo o mesmo não se verifica quando se considera o PIB da região Nordeste, pois houve uma perda de 2,0 p.p. pela ótica produção industrial e de 1,4 p.p. pela ótica do emprego, o que caracteriza como um processo de desindustrialização. Todavia, desindustrialização de que tipo?

Para isso foram utilizados os conceitos desenvolvidos por Silva (2017) e analisada a evolução da indústria nordestina em relação à indústria de transformação nacional. Com efeito, pode-se 
confirmar a existência de um processo de desindustrialização regional estagnada. Mas estagnada de que tipo? Com concentração ou desconcentração da produção e emprego industriais nos estados da região em foco?

Para responder a essa pergunta, foi necessário analisar a distribuição da produção e do emprego industrial, mas de forma desagregada. Diante desses dados, foi possível concluir que existe um processo de desindustrialização estagnada e negativa, dado que se observou uma concentração nos estados avançados.

Sendo assim, dada a importância da indústria de transformação para o desenvolvimento da região, é preciso reindustrializar o Nordeste, mas com uma indústria moderna e intensiva em capital e, ao mesmo tempo, de forma desconcentrada que leve a economia dos diversos estados e, portanto, da região Nordeste a aproveitar todos os benefícios mencionados por Hirschman (1958) e Kaldor (1967). Com efeito, somente dessa maneira que o descompasso entre as regiões do país será reduzido.

\section{REFERÊNCIAS}

ARAÚJO, T. A. Ensaios sobre o desenvolvimento brasileiro: heranças e urgências. Rio de Janeiro, Revan, 2000.

BARROS, O.; PEREIRA, R. R. Desmistificando a tese de desindustrialização: reestruturação da indústria brasileira em uma época de transformações globais. In: BARROS, O.; GIAMBIAGI, F. (Org.). Brasil globalizado: o Brasil em um mundo surpreendente. Rio de Janeiro: Elsevier, 2008. p. 299-330.

BONELLI, R.; PESSÔA, S. A. Desindustrialização no Brasil: um resumo da evidência. [S.I.]: FGV/IBRE, 2010. (Texto para Discussão, n. 7).

BONELLI, R.; PINHEIRO, A. C. Competividade e desempenho industrial: mais que só o câmbio. In: FÓRUM NACIONAL, 24., 2012, Rio de Janeiro. Anais [...]. Rio de Janeiro: INAE, 2012. Disponível em: http://www. inae.org.br/wp-content/uploads/2015/04/EP0432.pdf. Acesso em: 22 maio 2016.

BRESSER-PEREIRA, L. C. The Dutch disease and its neutralization: a Ricardian approach. Revista de Economia Política, São Paulo, v. 28, n. 1, p. 47-71), jan./mar. 2008.

BRESSER-PEREIRA, L. C.; MARCONI, N. Existe doença holandesa no Brasil? In: FÓRUM DE ECONOMIA DE SÃO PAULO, 4., 2008, São Paulo. Anais [...]. São Paulo: Fundação Getúlio Vargas, 2008. Disponível em: http://www.bresserpereira.org.br/papers/2008/08.14.Existe.doen\%C3\%A7a.holandesa.comNelson. Marconi.5.4.08.pdf. Acesso em: 22 jun. 2016.

CANO, W. (Des)industrialização e (sub)desenvolvimento. Cadernos do Desenvolvimento, Rio de Janeiro, v. 9, n. 15, p. 139-74, jul./dez. 2014.

CANO, W. Desequilibrios regionais e concentração industrial no Brasil: 1930-1970 e 1970-1995. Campinas, SP: UNICAMP, 1998.

HIRATUKA, C.; SARTI, F. Transformações na estrutura produtiva global, desindustrialização e desenvolvimento industrial no Brasil: uma contribuição ao debate. Campinas: IE Unicamp, 2015. (Texto para Discussão, n. 255).

HIRSCHMAN, A. O. The strategy of economic development. New Haven: Yale University Press, 1958.

IBGE. Contas nacionais e regionais. 2017. Disponível em: http://www.ibge.gov.br. Acesso em: jan. 2017. 
KALDOR, N. Problems of industrialization in underdeveloped countries. In: KALDOR, N. Strategic factors of economic development. New York: Cornell University Press, 1967. p. 53-72.

KALDOR, N. A model of economic growth. The Economic Journal, v. 67, n. 268. p. 591-624, dez. 1957.

NASSIF, A. Há evidências de desindustrialização no Brasil? Revista de Economia Política, São Paulo, v. 28, n. 1, p. 72-96, jan./mar. 2008.

OLIVEIRA, L. R.; SILVA, J. A. A desindustrialização e o capital especulativo na economia brasileira. Indicadores Econômicos FEE, Porto Alegre, v. 44, n. 2, p. 45-60, 2016.

OREIRO, J. L.; FEIJÓ, C. Desindustrialização: conceituação, causas, efeitos e o caso brasileiro. Revista de Economia Política, São Paulo, v. 30, n. 2, p. 219-32, abr./jun. 2010.

OREIRO, J. L.; MARCONI, N. Teses equivocadas no debate sobre desindustrialização e perda de competitividade da indústria brasileira. Revista NECAT, Florianópolis, v. 3, n. 5, p. 34-48, 2014.

PALMA, G. Four Sources of de-industrialization and a new concept of the dutch disease. In: OCAMPO, J. A. (Ed.). Beyond reforms: structural dynamics and macroeconomic vulnerability. Stanford, EUA: Stanford University Press, 2005. p. 1-55.

PRADO, S. Guerra e políticas de desenvolvimento estadual no Brasil. 2000. 38p. (Ensaio que resume os resultados de ampla pesquisa sobre o tema, realizado na Diretoria de Economia do Setor Público da FUNDAP - Fundação para o Desenvolvimento Administrativo).

RELAÇÃO ANUAL DE INFORMAÇÕES SOCIAIS (RAIS). 2017. Disponível em: http://www.mte.gov.br/geral/ estatisticas.asp?viewarea=caged. Acesso em: jan. 2017.

ROWTHORN, R.; WELLS, J. De-industrialisation and foreign trade. Cambridge, Reino Unido: Cambridge University Press, 1987.

SAMPAIO, D. P. Desindustrialização e estruturas produtivas regionais no Brasil. 2015. Tese (Doutorado em Desenvolvimento Econômico) - Universidade Estadual de Campinas (UNICAMP), Campinas, SP, 2015.

SILVA, J. A.; LOURENÇO, A. L. C. Desindustrialização em debate: teses e equívocos no caso da economia brasileira. Indicadores Econômicos FEE, Porto Alegre, v. 42, n. 2, p. 57-76, 2014.

SILVA, J. A. Desindustrialização regional: conceitos, causas, efeitos e o caso brasileiro. 2017. (Mimeo).

SQUEFF, G. C. Desindustrialização: luzes e sombras no debate brasileiro. Brasília: IPEA, 2012. (Texto para Discussão 1747). Disponível em: http://repositorio.ipea.gov.br/bitstream/11058/1125/1/TD_1747.pdf

TREGENNA, F. Characterizing deindustrialization: an analysis of changes in manufacturing employment and output internationally. Cambridge Journal of Economics, Oxford, UK, v. 33, n. 3, p. 433-66, maio 2009.

VERGNHANINI, R. O debate sobre a mudança estrutural da economia brasileira nos anos 2000. 2013. Dissertação (Mestrado em Economia Política Internacional) - Universidade Federal do Rio de Janeiro (UFRJ), Rio de Janeiro, 2013. 


\section{Sobre o autor:}

José Alderir da Silva: Mestre e Graduado em Economia pela Universidade Federal do Rio Grande do Norte (UFRN). Professor de Economia na Universidade Federal do Semi-Árido (UFERSA). E-mail: josealderir16@hotmail.com 